\title{
Efeito da suplementação nas características de carcaça e dos componentes não-carcaça de caprinos F1 Boer $\times$ SRD terminados em pastagem nativa ${ }^{1}$
}

\author{
Aloísio Monteiro de Carvalho Júnior ${ }^{2}$, José Morais Pereira Filho ${ }^{3}$, Rayana de Medeiros \\ Silva ${ }^{2}$, Marcílio Fontes Cezar ${ }^{3}$, Aderbal Marcos de Azevêdo Silva ${ }^{3}$, Anderson Luiz \\ Nascimento da Silva ${ }^{2}$
}

\footnotetext{
1 Projeto financiado pelo CNPq.

2 Pós-graduação em Zootecnia - Universidade Federal de Campina Grande (UFCG).

${ }^{3}$ Departamento de Veterinária - Universidade Federal de Campina Grande (UFCG).
}

RESUMO - Objetivou-se avaliar o efeito da suplementação nas características de carcaça de cabritos F1 Boer $\times$ SRD terminados em pastagem nativa. Foram utilizados 24 caprinos F1 Boer $\times$ SRD, não-castrados, com 120 dias de idade e com peso vivo inicial de $15,52 \mathrm{~kg}$. Os animais foram identificados, vermifugados e distribuídos de forma aleatória em quatro níveis de suplementação $(0,0 ; 0,5 ; 1,0$ e 1,5\%), perfazendo seis repetições por tratamento. O manejo alimentar consistiu de pastejo com lotação contínua das $7 \mathrm{~h} 30$ às $16 \mathrm{~h}$, quando os animais foram recolhidos às baias para suplementação em gaiolas individuais equipadas com cochos e bebedouros. O trato gastrintestinal (TGI) foi pesado cheio e vazio, assim como a bexiga e a vesícula biliar, para obtenção do peso de corpo vazio (PCV). O rendimento dos órgãos e das vísceras apresentou tendência diferente à observada para peso absoluto, exceto para rendimento das patas, que apresentou comportamento linear decrescente. Os pesos e os rendimentos da carcaça quente e fria, bem como o peso do corpo vazio e o rendimento biológico, apresentaram resposta positiva aos níveis de suplementação. Na análise da participação dos cortes comerciais na carcaça, apenas o rendimento do pescoço aumentou de forma linear com o aumento dos níveis de suplementação. Os pesos do trato gastrintestinal cheio e do conteúdo gastrintestinal não responderam aos níveis de suplementação. O peso do conteúdo gastrintestinal foi determinante para o efeito da suplementação no peso do trato gastrintestinal cheio. O peso de todos os cortes comerciais respondeu de forma positiva à suplementação.

Palavras-chave: abate, forragem, morfometria, paleta

\section{Effect of supplemental feeding on carcass and non-carcass characteristics of F1 (Boer $\times$ SRD) goats finished on native pasture}

\begin{abstract}
The objective of this study was to evaluate the effect of supplementation on the carcass characteristics of crossbred Boer goats finished on native pasture. Twenty-four Boer crossbreed goats were used, 120 days old and with an initial $15.52 \mathrm{~kg}$ BW. The supplemental feeding was randomly assigned to the animals according to a completely randomized design with 4 supplementation levels (0.0, 0.5, 1.0 and 1.5\%) and six replications (goats). The animals had access to the pasture from 7:30 a.m. until 4 p.m. throughout the experimental period and were taken to stalls to receive supplemental feeding in individual cages equipped with hods and a water. Full and empty digestive tract (DT) were weighed, as well as the bladder and gall bladder to obtain the empty body weight (EBW). The visceras yield tended to be different from that observed for absolute weight, except for hoof yield that presented a decreasing linear behavior. The hot and cold carcass weights and the yields and the empty body weight and the biological yield presented positively response to the supplementation levels. Regarding the participation of wholesale cuts in the carcass, only the neck yield presented linear effect in response to the increase in supplementation levels. Full digestive tract and digestive content weights did not respond to the supplementation levels. The digestive content weight was decisive for the effect of supplemental feeding in the full digestive tract weight. Wholesale cuts weight responded positively to the supplementation levels.
\end{abstract}

Key Words: forage, morfometry, shoulder, slaughter 


\section{Introdução}

Na Região Nordeste, a caprinocultura se caracteriza pela subsistência e por fornecer proteína de alto valor biológico a populações de baixa renda, mas a maioria dos produtores ainda mantém sistemas de produção com baixos índices produtivos.

Entre as medidas adotadas por pesquisadores e produtores para melhorar o desempenho produtivo dos rebanhos caprinos, a seleção e/ou a utilização de cruzamentos de raças especializadas com os animais nativos da região têm se tornado cada vez mais presentes. Lucas (2007) destaca que a conformação da carcaça é influenciada pela base genética e que as raças com aptidão para produção de carne, com boa conformação corporal, transmitem melhor a boa conformação da carcaça à sua descendência. Nos últimos anos, o setor tem experimentado alguns avanços na melhoria do rebanho, sobretudo a introdução de raças exóticas, como a raça Boer (Madruga et al., 2005).

Segundo Gonzaga Neto et al. (2006), o desempenho e as características da carcaça são influenciados diretamente pela composição nutricional da dieta. Como a produção de carne depende do genótipo e do ambiente em que o animal é criado (Barros et al., 1992), o uso de suplementação com concentrado na época de escassez das chuvas é importante para o melhor aproveitamento da dieta total, principalmente em pastagem nativa, que se caracteriza por elevada variação em sua composição química ao longo do ano.

De acordo com Santos et al. (2001), avaliação da carcaça é uma importante análise do desempenho alcançado pelo animal durante seu desenvolvimento e é determinada a partir do consumo, do ganho de peso, da conversão alimentar e do rendimento de carcaça. O sistema de produção de carne é avaliado pelas características quantitativas e qualitativas da carcaça; as características quantitativas são determinadas pelo rendimento, a composição regional, a composição tecidual e a musculosidade da carcaça (Lucas, 2007).

Além da carcaça, no Nordeste do Brasil, é comum a utilização de órgãos e vísceras na culinária regional, pois os componentes não-carcaça representam mais uma alternativa alimentar como fonte de proteína de origem animal, sobretudo para as populações menos favorecidas (Mattos et al., 2006).

Este trabalho foi realizado com o objetivo de avaliar o efeito da suplementação nas características de carcaça de cabritos F1 (Boer $\times$ SRD) terminados em pastagem nativa.

\section{Material e Métodos}

O experimento foi conduzido no Centro de Saúde e Tecnologia Rural (CSTR) da Universidade Federal de Campina Grande (UFCG), Campus de Patos, Paraíba, Brasil. A fase de campo foi realizada no Núcleo de Pesquisa para o Desenvolvimento do Semiárido (Nupeárido) e as análises químicas, no laboratório de Nutrição animal do CSTR/UFCG. A área experimental foi de 1,5 hectare, geograficamente localizada nas coordenadas Latitude S - $7^{\circ}$ 4' 44.4", Longitude W - $37^{\circ} 16^{\prime} 28.5^{\prime \prime}$ e altitude de $262 \mathrm{~m}$.

O clima da região, segundo classificação de Koppen, é do tipo BShw' - semiárido, com curta estação chuvosa no verão-outono e precipitações concentradas nos meses de março e abril, porém a estação chuvosa pode ocorrer de janeiro a maio. A precipitação pluvial no período experimental variou de 11 a $118,3 \mathrm{~mm}$ e a temperatura média, de $26,6^{\circ} \mathrm{C}$ a $29,4^{\circ} \mathrm{C}$, enquanto o maior índice de umidade observado alcançou $60 \%$ na fase inicial do período experimental.

A vegetação da área experimental é caracterizada pela presença de espécies lenhosas nativas e exóticas que, juntas, representam em torno de 10 a $15 \%$ de cobertura do solo. Na composição botânica do estrato herbáceo, destacam-se gramíneas como as milhãs (Brachiaria plantaginea e Panicum sp.), capim-buffel (Cenchrus ciliares L), capim-rabo-de-raposa (Setaria sp.) e capimpanasco (Aristida setifolia H.B.K.); dicotiledôneas, como malva-branca (Cassia uniflora), alfazema-brava (Hyptis suaveolens Point), mata-pasto (Senna obtusifolia (L.) HS Irwin \& Barneby) e erva-de-ovelha (Stylozanthes sp.).

Foram utilizados 24 caprinos F1 (Boer $\times$ SRD), nãocastrados, com 120 dias de idade e peso vivo inicial de $15,52 \mathrm{~kg}$. Os animais foram identificados com brincos/ coleiras, vermifugados e distribuídos de forma aleatória em quatro níveis de suplementação $(0,0 ; 0,5 ; 1,0$ e 1,5\%), perfazendo seis repetições por tratamento. Os animais foram mantidos em um único piquete de 1,5 hectare, cercado com tela de arame e provido de água e mistura mineral completa. A fase de campo durou 98 dias (14 de adaptação e 84 de experimento).

O manejo alimentar consistiu de pastejo com lotação contínua das $7 \mathrm{~h} 30$ às $16 \mathrm{~h}$, quando eram recolhidos às baias para suplementação em gaiolas individuais equipadas com cochos e bebedouros. Após o início do experimento, a cada 14 dias, foram coletadas fezes para avaliação da carga parasitária e toda vez que os resultados indicavam carga igual ou superior a 500 ovos por grama (OPG) era realizada a vermifugação. O desempenho foi acompanhado 
Tabela 1 - Composição química dos ingredientes e da mistura total utilizada no suplemento oferecido aos animais

\begin{tabular}{|c|c|c|c|c|}
\hline Ingrediente e mistura total & Matéria seca (\%) & Energia bruta (Mcal/kg) & Proteína bruta (\%) & Cinzas (\%) \\
\hline Torta de algodão & 94,22 & 5,21 & 26,40 & 6,23 \\
\hline Milho moído & 45,46 & 4,32 & 8,83 & 1,13 \\
\hline Óleo de soja & - & 8,31 & - & - \\
\hline Calcário & 99 & - & - & 99 \\
\hline Núcleo mineral* & 99 & - & - & 99 \\
\hline
\end{tabular}

*Cálcio - 130 g; Fósforo - 75 g; Magnésio - 5 g; Ferro - 1.500 mg; Cobalto - 100 mg; Cobre - 275 mg; Manganês - 1.000 mg; Zinco - 2.000 mg; Iodo - 61 mg; Selênio - 11 mg; Enxofre - 14 g; Sódio - 151 g; Cloro - 245 g; Flúor máximo - 175 g.

por meio de pesagem realizada a cada 14 dias, sempre às 7 h30 da manhã, precedida de jejum de 16 horas, visando monitorar o ganho de peso dos animais.

A ração experimental foi constituída de milho moído (53,21\%), farelo de trigo (24,43\%), torta de algodão (13,61\%), farelo de soja (3,76\%), óleo de soja (1,75\%), calcário (1,5\%), núcleo mineral para caprinos $(1,74 \%)$, com mistura feita de forma manual (Tabela 1). O balanceamento da ração foi realizado segundo recomendações do AFRC (1998), de modo que o maior nível de suplementação promovesse ganho de 200 g por dia.

Para avaliação da disponibilidade de matéria seca, a vegetação herbácea foi separada em gramíneas e dicotiledôneas herbáceas e avaliada em três períodos: início, após período de adaptação de 16 dias (28/5/2007); meio (9/7/2007); e final (6/8/2007) do período experimental. Em cada período de avaliação, foram realizadas 20 amostras para estimativas da disponibilidade de matéria seca dos componentes do estrato herbáceo, feitas a partir de transectos traçados segundo o sentido Norte, Sul, Leste e Oeste do ponto central do piquete e utilizando como unidade amostral uma moldura de ferro medindo $1,00 \mathrm{~m} \times 0,25 \mathrm{~m}$, conforme metodologia preconizada por Araújo Filho et al. (1991). A partir dos resultados obtidos com a moldura, foi feita a estimativa de disponibilidade de matéria seca por hectare (Tabela 2), da disponibilidade da composição florística e da digestibilidade da MS de gramíneas e dicotiledôneas durante o período experimental.
Em cada período de avaliação, foram constituídas amostras compostas dos componentes gramíneas e dicotiledôneas herbáceas, as quais foram secas em estufa de circulação forçada por 72 horas, resfriadas a temperatura ambiente e moídas para análises de matéria seca (MS), proteína bruta (PB), matéria mineral (MM), energia bruta (EB), fibra detergente neutro (FDN) e fibra detergente ácido (FDA), de acordo com metodologia descrita por Silva \& Queiroz (2002).

O abate e a avaliação da carcaça foram realizados no abatedouro de pequenos ruminantes. Ao completarem 84 dias de experimento, os animais foram submetidos a jejum de sólidos (24 horas) e líquidos (16 horas) e, ao final do jejum, foram abatidos por concussão cerebral e secção da veia jugular, seguida de esfola e evisceração. Terminado o processo de evisceração e retirada dos órgãos, procedeu-se à separação das mãos e dos pés na articulação carpometacarpiana e tarsometatarsiana, respectivamente, para obtenção do peso da carcaça quente (PCQ).

O trato gastrintestinal (TGI) foi pesado cheio e vazio, assim como a bexiga e vesícula biliar, para obtenção do peso do corpo vazio (PCV), obtido subtraindo do peso ao abate os pesos referentes aos conteúdos gastrintestinais, biliares e da bexiga. Os componentes do corpo do animal não incluídos no peso da carcaça foram denominados "não-componentes da carcaça" e foram obtidos da subtração do peso da carcaça do peso do corpo vazio $(\mathrm{NCC}=\mathrm{PC}-\mathrm{PCV})$.

Tabela 2 - Disponibilidade de MS (kg/ha), Composição florística (\%) e digestibilidade de matéria seca de gramíneas e dicotiledôneas da área experimental

\begin{tabular}{|c|c|c|c|c|c|c|c|c|}
\hline Período & \multicolumn{3}{|c|}{ Disponibilidade de matéria seca (kg/ha) } & \multicolumn{3}{|c|}{ Composição florística (\%) } & \multicolumn{2}{|c|}{ Digestibilidade da matéria seca $(\%)^{*}$} \\
\hline Início & $1.102,89$ & $1.759,46$ & $2.862,36$ & 38,53 & 42,35 & 88,60 & 47,95 & 52,54 \\
\hline Fim & $1.494,81$ & 192,30 & $1.687,11$ & 100,00 & 100,00 & 100,00 & 41,20 & 51,80 \\
\hline
\end{tabular}

*Obtido pelo FDNi (Berchielli et al., 2000). 
O peso de carcaça quente foi utilizado para estimar o rendimento da carcaça quente $(\mathrm{RCQ}=\mathrm{PCQ} / \mathrm{PVA} \times 100)$ e o rendimento biológico/verdadeiro $(\mathrm{RB}=\mathrm{PCQ} / \mathrm{PCV} \times 100)$. As carcaças foram identificadas e resfriadas a temperatura de 3 a $5^{\circ} \mathrm{C}$ por 24 horas, penduradas pelo tendão calcânio. Ao final do resfriamento, as carcaças foram novamente pesadas para obtenção do peso da carcaça fria (PCF) e estimativa da perda de peso pelo processo de resfriamento $(P P R=P C Q-P C F / P C Q \times 100)$ e do rendimento da carcaça fria $(\mathrm{RCF}=\mathrm{PCF} / \mathrm{PVA} \times 100)$.

A morfometria foi utilizada como parâmetro para predição da conformação da carcaça. A avaliação da morfometria da carcaça foi realizada após o abate e resfriamento da carcaça, segundo metodologia descrita por Cezar \& Souza (2007), e consistiu dos comprimentos da carcaça (interna e externa) e da perna, das larguras da garupa e do tórax, da profundidade do tórax e do perímetro da garupa e da perna. Todas as medidas de comprimento e de perímetro foram feitas com fita métrica, e as da largura, com compasso.

As carcaças foram seccionadas de forma longitudinal, dando origem a duas meias-carcaças, com cinco cortes na meia-carcaça esquerda para obtenção dos cortes comerciais: perna, lombo, costelas, paleta e pescoço, adaptando-se as metodologias de Colomer-Rocher et al. (1987), Osório et al. (1998) e Yáñez (2002).

O delineamento utilizado foi o inteiramente casualizado, com quatro tratamentos e seis repetições. Os dados foram submetidos a análises de variância e regressão, sempre a
5\% de probabilidade. O processamento dos dados estatísticos foi feito utilizando-se o programa estatístico SAS (1999).

\section{Resultados e Discussão}

Os pesos do trato digestivo vazio, dos rins, do fígado, do trato respiratório, do coração, do sangue e das patas foram influenciados $(\mathrm{P}<0,05)$ pelo nível de suplementação e aumentaram linearmente de acordo com o nível de suplementação (Tabela 3). Um aumento de 1\% na suplementação em MS com base no peso vivo dos cabritos permitiu estimar o acréscimo de 0,$52 ; 0,01 ; 0,06 ; 0,08 ; 0,01$; 0,14 e 0,06 kg para peso do trato disgestivo, dos rins, do fígado, trato respiratório, coração, sangue e das patas, respectivamente.

O rendimento dos órgãos e das vísceras apresentou tendência diferente da observada para peso absoluto, exceto para rendimento das patas, que apresentou comportamento linear decrescente, de modo que $1 \%$ de aumento no nível de suplementação com base no peso vivo para caprinos em pastejo promoveu decréscimo de $0,53 \%$. O rendimento do trato digestivo apresentou comportamento quadrático crescente até o nível de 0,9\% de suplementação, seguido de decréscimo até o nível de $1,5 \%$ de suplementação.

O efeito linear da suplementação no peso de todos os órgãos e a não-confirmação desse efeito nos rendimentos (exceto para trato digestivo e patas) pode ser relacionado

Tabela 3 - Peso e rendimento dos órgãos e das vísceras de caprinos mestiços F1 (Boer × SRD) terminados em pastagem nativa com diversos níveis de suplementação

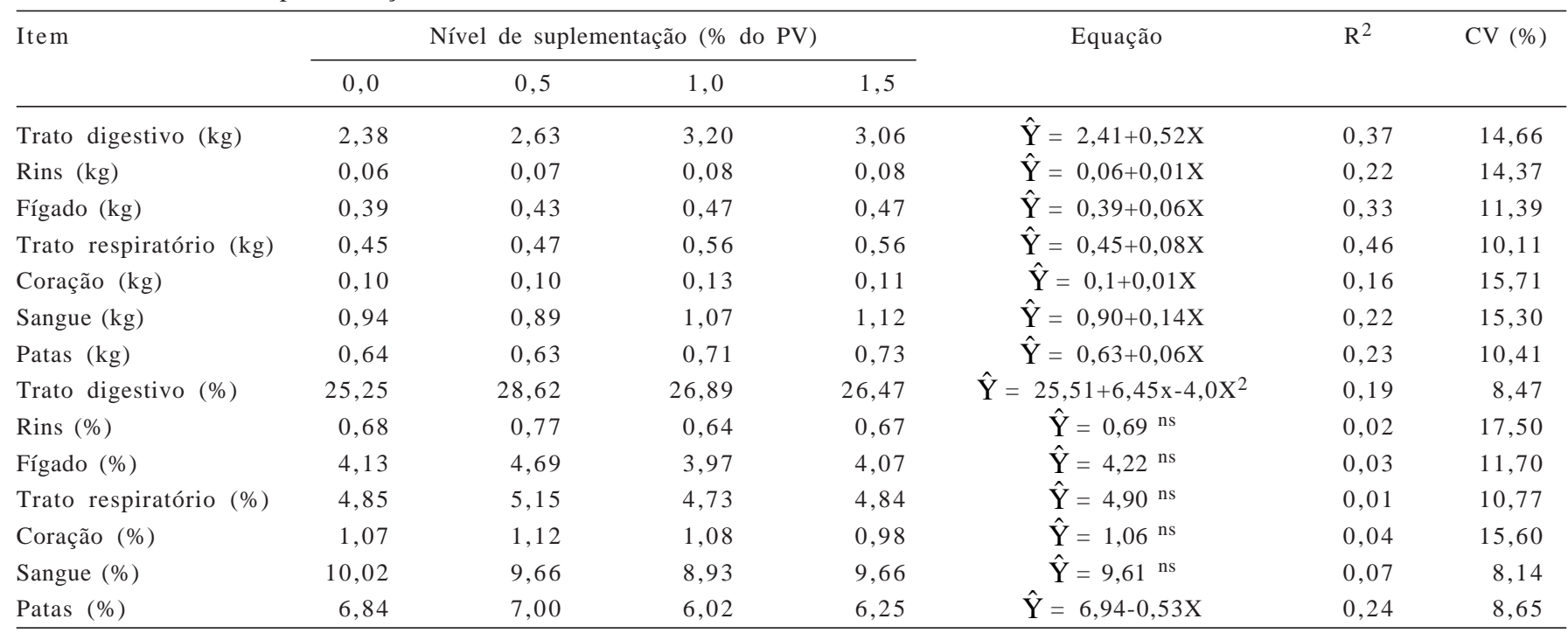

$\hat{\mathrm{Y}}$ = variável dependente e $\mathrm{X}$ = variável independente (nível de suplementação). 
à diferença no crescimento da carcaça em relação aos nãocomponentes da carcaça (Yáñez, 2002), o que fica mais claro no efeito quadrático observado para o trato digestivo, que parece refletir o crescimento rápido do TGI na fase final do desmame/desaleitamento e a consequente estabilização na fase adulta. O efeito linear decrescente da suplementação no rendimento das patas pode ser explicado pela sua maior proporção de osso, e ser este um tecido de crescimento precoce em relação ao músculo e à gordura contida na carcaça (Boggs et al., 1998).

Comparando diferentes sistemas de alimentação (campo nativo, pastagem cultivada e concentrado) em cordeiros da raça Ideal e Corriedale, Osório et al. (1998) observaram que os cordeiros mantidos em pastagem nativa apresentaram maior proporção de vísceras em comparação àqueles mantidos em pastagem cultivada ou com concentrado, e pastagem nativa com suplementação concentrada. Mattos et al. (2006) avaliaram características de carcaça e dos nãocomponentes da carcaça de cabritos Moxotó e Canidé submetidos a dois níveis de alimentação e observaram que a influência do nível de alimentação sobre o peso de órgãos de crescimento precoce, como coração, fígado, pulmão e rins, foi maior no mais alto nível de consumo dos animais alimentados à vontade, diferentemente do que ocorreu com os animais F1 (Boer $\times$ SRD), que, mesmo apresentando consumo total de matéria seca crescente com o nível de concentrado (539,43; 632,59; 727,57 e 935,36 g de MS), não apresentaram diferença no rendimento desses órgãos.

Rosa et al. (2002) avaliaram proporções e coeficientes dos não-componentes da carcaça de cordeiros e cordeiras em três métodos de alimentação - o primeiro com silagem de milho mais creep feeding até o desmame (60 dias); o segundo igual ao primeiro diferindo apenas no desmame (45 dias); e o terceiro com silagem de milho e concentrado com proporção de 70:30 na MS para o conjunto ovelha e cordeiro até os desmame (60 dias) - e não verificaram diferença significativa nos valores percentuais de órgãos de crescimento precoce, como coração e fígado, o que foi, de certa forma, confirmado pelos resultados obtido com os mestiços F1 (Boer $\times$ SRD).

Kouakou et al. (1997) destacaram que o efeito da dieta nos tecidos viscerais, em relação ao peso do corpo vazio, é o somatório de várias condições, incluindo a função de absorção e as funções associadas aos tecidos periféricos e aos componentes da carcaça, o que pode resultar em efeito direto no peso e no rendimento de alguns órgãos. Esse aspecto foi ressaltado por Fuenmayor \& Clavero (1999), que constataram carcaças, rins e fígado mais pesados nos cordeiros que receberam suplementação em comparação aos obtidos com animais sem suplementação.

Neste trabalho, houve influência $(\mathrm{P}<0,05)$ dos níveis de suplementação na largura e profundidade do tórax, enquanto o comprimento externo da carcaça, a largura da garupa, a profundidade da perna, a profundidade da garupa, o comprimento interno da carcaça e o comprimento da perna não variaram estatisticamente com o aumento do nível de suplementação (Tabela 4).

O efeito linear da suplementação na largura, profundidade e no perímetro do tórax pode estar relacionado ao efeito linear do trato gastrintestinal (Tabela 5). Dessa forma, esses resultados confirmam os obtidos por Yáñez et al. (2004), que avaliaram a predição de características de carcaça a partir de medidas biométricas em cabritos Saanen abatidos com peso vivo entre 15 e $35 \mathrm{~kg}$ e verificaram que, entre as medidas estudadas, o perímetro torácico foi a que melhor estimou o peso da carcarça fria.

Os pesos e os rendimentos da carcaça quente e fria, bem como o peso do corpo vazio e o rendimento biológico

Tabela 4 - Morfometria da carcaça de caprinos terminados em pastagem nativa com diversos níveis de suplementação

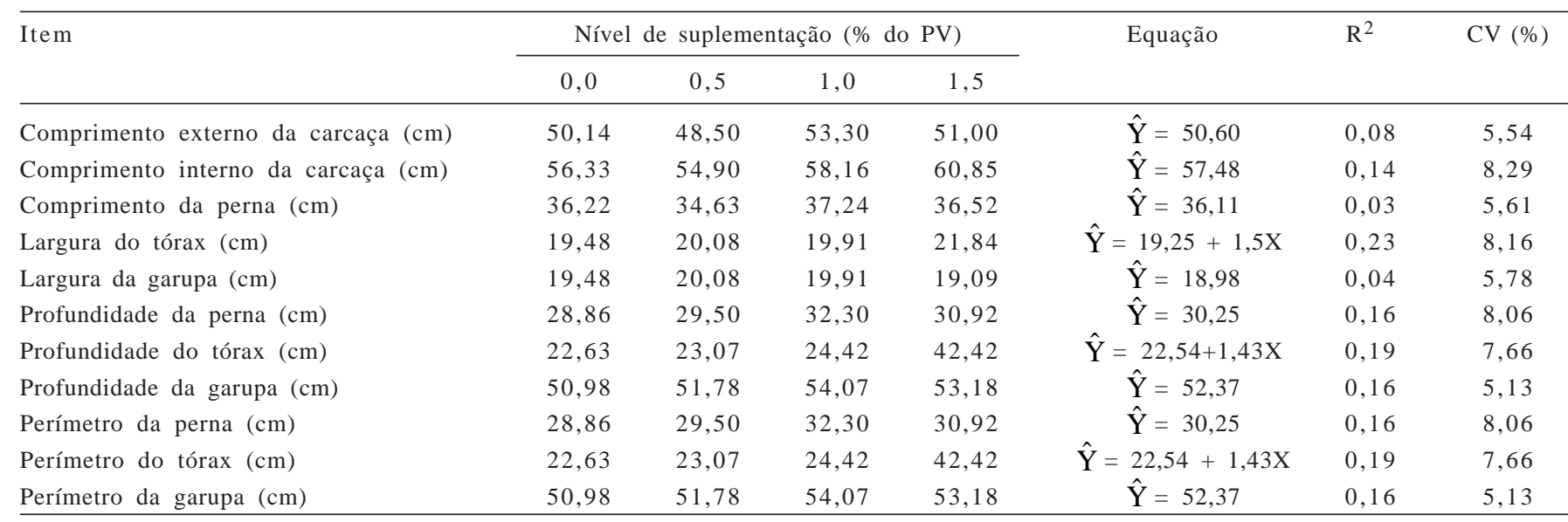

$\hat{\mathrm{Y}}$ = variável dependente e $\mathrm{X}$ = variável independente (nível de suplementação). 
Tabela 5 - Peso e rendimento da carcaça, pesos do trato e do conteúdo gastrintestinal de caprinos F1 (Boer $\times$ SRD) terminados em pastagem nativa com diferentes níveis de suplementação

\begin{tabular}{|c|c|c|c|c|c|c|c|}
\hline Item & \multicolumn{4}{|c|}{ Nível de suplementação (\% do PV) } & Equação & $\mathrm{R}^{2}$ & CV (\%) \\
\hline Carcaça quente (kg) & 9,90 & 10,45 & 12,40 & 12,70 & $\hat{\mathrm{Y}}=9,685+2,207 \mathrm{X}$ & 0,316 & 17,35 \\
\hline Meia carcaça esquerda (kg) & 4,68 & 4,87 & 5,83 & 5,90 & $\hat{\mathrm{Y}}=4,581+0,977 \mathrm{X}$ & 0,293 & 17,30 \\
\hline Trato gastrintestinal cheio (kg) & 7,97 & 8,82 & 8,48 & 8,72 & $\hat{\mathrm{Y}}=8,478$ & 0,060 & 14,43 \\
\hline Corpo vazio (kg) & 19,49 & 20,56 & 23,07 & 23,53 & $\hat{Y}=19,313+3116 X$ & 0,271 & 14,25 \\
\hline Biológico (\%) & 50,62 & 50,56 & 53,53 & 53,71 & $\hat{\mathrm{Y}}=50,222+2,493 \mathrm{X}$ & 0,290 & 4,50 \\
\hline Carcaça quente (\%) & 39,43 & 38,80 & 43,44 & 43,26 & $\hat{\mathrm{Y}}=38,854+3,124 \mathrm{X}$ & 0,323 & 6,61 \\
\hline Carcaça fria (\%) & 37,22 & 36,41 & 39,98 & 39,90 & $\hat{\mathrm{Y}}=36,683+2,233 \mathrm{X}$ & 0,290 & 5,49 \\
\hline
\end{tabular}

$\hat{\mathrm{Y}}$ = variável dependente e $\mathrm{X}$ = variável independente (nível de suplementação).

(Tabela 5), apresentaram resposta positiva $(\mathrm{P}<0,05)$ aos níveis de suplementação. Esse comportamento também foi observado por Carvalho et al. (2006) quando avaliaram o desempenho e as características de cordeiros mantidos em pastagem de capim-tifton 85 com suplementação nos níveis $0 ; 1 ; 1,5 ; 2$ e 2,5\% do peso vivo.

Os pesos do trato gastrintestinal cheio e do conteúdo gastrintestinal não responderam $(\mathrm{P}>0,05)$ à suplementação. O peso do conteúdo gastrintestinal foi determinante do peso do trato gastrintestinal cheio, que, depois de vazio, aumentou com os níveis de suplementação. Esses resultados reforçam os observados por Mattos et al. (2006), que, avaliando características de carcaça e dos componentes não-carcaça de cabritos das raças Moxotó e Canidé submetidos a dois níveis de alimentação, concluíram que a quantidade de alimento ingerida durante o período experimental foi responsável pelo maior desenvolvimento $(\mathrm{kg})$ do trato gastrintestinal vazio. Além disso, as diferenças no peso observadas para conteúdo do trato gastrointestinal contribuíram para aumento de 46 para $48,1 \%$ no peso de corpo ao abate, respectivamente, para animais com alimentação restrita e alimentação vontade, o que comprova que o trato gastrintestinal é determinante do rendimento de carcaça.

Tavares et al. (2005) trabalhando com níveis crescentes de feno na dieta de caprinos afirmaram que o aumento dos níveis de fibra da dieta reduz a digestibilidade e o consumo de MS, o que resulta no enchimento do trato gastrointestinal, fazendo com que o alimento permaneça por mais tempo no rúmem, aumentando o conteúdo do TGI e diminuindo a eficiência produtiva do animal. Nesse sentido, o bom desempenho dos animais sem suplementação pode ser associado à alta disponibilidade e à qualidade da forragem, uma vez que, no início do experimento, as gramíneas apresentavam 1.102,89 kg/ha de MS, 9,8\% de PB e digestibilidade de $65,98 \%$ e, no caso das dicotiledôneas existentes na pastagem, que, normalmente são mais preferidas pelos caprinos que as gramíneas, apresentavam os valores de 1.759,46 kg/ha de MS com 12,42\% de PB e digestibilidade de $66,78 \%$, o que favoreceu o consumo pelos animais.

Warmington \& Kirton (1990) afirmaram que a nutrição e os pesos do conteúdo gastrointestinal e órgãos internos influenciam o rendimento da carcaça e que o aumento do teor de fibra da dieta eleva o tempo de retenção do alimento no trato digestório, resultando em menor rendimento da carcaça, o que explica o menor rendimento de carcaça dos animais sem suplementação. Os mestiços F1 (Boer × SRD) criados em pastagem nativa e suplementados com 1,5\% do peso vivo apresentaram $43,26 \%$ de rendimento de carcaça quente, valores inferiores aos 47,1 e $47,7 \%$ obtidos por Pereira Filho et al. (2005), com cabritos mestiços F1 (Boer $\times$ Saanen) submetidos a dois níveis de restrição alimentar ( $0 \%$ e $30 \%$ ) criados em confinamento e abatidos com $23 \mathrm{~kg}$ de peso.

O peso de todos os cortes comerciais respondeu de forma positiva $(\mathrm{P}<0,05)$ à suplementação, o que também foi observado por Carvalho et al (2005) em ovinos recebendo suplementação nos níveis 0,$0 ; 1 ; 1,5 ; 2$ e 2,5\% do peso vivo mantidos em pastagem de capim-tifton 85 (Tabela 6). Na avaliação do rendimento (\%) dos cortes comerciais na carcaça, apenas o rendimento do pescoço teve efeito linear do aumento dos níveis de suplementação. Esse comportamento pode ser reflexo da condição fisiológica dos animais, pois eram animais jovens, não-castrados, e que geralmente apresentam a região do pescoço bem desenvolvida. 
Tabela 6 - Peso e rendimento dos cortes comerciais de caprinos F1 (Boer × SRD) terminados em pastagem nativa com diferentes níveis de suplementação

\begin{tabular}{|c|c|c|c|c|c|c|c|}
\hline \multirow[t]{2}{*}{ Corte } & \multicolumn{4}{|c|}{ Nível de suplementação (\% do PV) } & \multirow[t]{2}{*}{ Equação } & \multirow[t]{2}{*}{$\mathrm{R}^{2}$} & \multirow[t]{2}{*}{ CV (\%) } \\
\hline & 0,0 & 0,5 & 1,0 & 1,5 & & & \\
\hline Perna (kg) & 1,47 & 1,48 & 1,58 & 1,75 & $\hat{\mathrm{Y}}=1,427+0,200 \mathrm{X}$ & 0,21 & 14,59 \\
\hline Costilhar (kg) & 1,11 & 1,19 & 1,43 & 1,40 & $\hat{\mathrm{Y}}=1,106+0,230 \mathrm{X}$ & 0,26 & 18,33 \\
\hline Paleta (kg) & 1,00 & 1,06 & 1,26 & 1,25 & $\hat{\mathrm{Y}}=0,999+0,192 \mathrm{X}$ & 0,30 & 15,30 \\
\hline Lombo (\%) & 13,11 & 13,32 & 13,36 & 13,38 & $\hat{\mathrm{Y}}=13,282$ & 0,0085 & 8,81 \\
\hline Costilhar (\%) & 23,91 & 24,06 & 25,67 & 23,61 & $\hat{\mathrm{Y}}=24,244$ & 0,0024 & 5,36 \\
\hline Paleta (\%) & 21,58 & 22,08 & 22,33 & 21,18 & $\hat{\mathrm{Y}}=21,765$ & 0,0075 & 5,69 \\
\hline Pescoço (\%) & 9,84 & 9,79 & 10,62 & 11,81 & $\hat{Y}=9,545+1,330 X$ & 0,28 & 12,51 \\
\hline
\end{tabular}

$\hat{\mathrm{Y}}$ = variável dependente e $\mathrm{X}$ = variável independente (nível de suplementação).

A participação dos cortes na carcaça permite uma avaliação qualitativa, pois deve apresentar a melhor proporção possível de cortes com maior conteúdo de tecidos comestíveis, principalmente músculos (Yáñez, 2002). Os animais F1 (Boer $\times$ SRD) apresentaram rendimento de perna em torno de $30 \%$, o que pode ser considerado satisfatório, pois eram de elevada rusticidade, terminados em pastagem nativa e abatidos com 25,12 a 29,19 kg de peso vivo.

Monte et al. (2007) avaliaram o rendimento dos cortes comerciais de cabritos mestiços Boer e Anglo Nubiano e de cabritos SRD e observaram que os cortes perna, lombo e paleta apresentaram maiores rendimentos em relação ao peso da meia-carcaça fria. $\mathrm{O}$ fato esteve relacionado à maior quantidade de tecido muscular desses cortes. Neste trabalho, os maiores valores alcançados foram para rendimento de perna, costilhar e paleta, com médias de 30,07; 24,31 e $21,79 \%$ respectivamente.

Mattos et al. (2006), avaliando carcaça e componentes não-carcaça de caprinos Moxotó e Canidé abatidos com 25 $\mathrm{kg}$, concluíram que a soma da porcentagem dos cortes de maior valor comercial (perna, paleta e lombo) não foi influenciada pelos níveis de alimentação, chegando a representar 58,8\% da soma das meias-carcaças nos animais com alimentação à vontade. O somatório dos rendimentos da perna e paleta dos animais F1 (Boer $\times$ SRD) sob suplementação nos níveis 0,$0 ; 0,5 ; 1,0$ e 1,5\% foram de 53,$13 ; 52,81 ; 50,33$ e $51,19 \%$, respectivamente, próximo dos 52,3 e 49,7\% observados por Colomer-Rocher et al. (1992) em caprinos Saanen não-castrados com 10 e 20 kg de peso vivo, no entanto, o rendimento da paleta diminuiu com o aumento do peso da carcaça, diferentemente do observado nos animais F1 (Boer $\times$ SRD), que, apesar de abatidos com $25,12 \mathrm{~kg}(0 \%), 26,62 \mathrm{~kg}(0,5 \%), 28,56 \mathrm{~kg}(1,0 \%)$ e 29,19 kg (1,5\%), não apresentaram diferença no rendimento.

\section{Conclusões}

A suplementação de animais F1 (Boer $\times$ SRD) possibilita a obtenção de animais com maiores pesos de órgãos (com exceção do trato gastrintestinal cheio e vazio), de carcaças e de cortes comerciais, além de aumentar os rendimentos de carcaça e de pescoço. Como os resultados indicam maior impacto da suplementação entre os níveis zero e $1 \%$, recomenda-se para obtenção de carcaça mais pesadas suplementação com níveis abaixo de 1,5\% do peso vivo.

\section{Literatura Citada}

AMARAL, C.M.C.; PELICANO, E.R.L.; YÁÑEZ, E.A. et al. Características de carcaça e qualidade de carne de cabritos Sannen alimentados com ração completa farelada, peletizada e extrusada. Ciência Rural, v.37, n.2, p.550-556, 2001.

BARROS, N.N.; KAWAS, J.R; LOPES, E.A. et al. Estudo comparativo da digestibilidade de leguminosa nativa com caprinos e ovinos, no semi-árido do estado do Ceará II Digestibilidade in vivo da silagem de mata-pasto (Cássia $s s p$ ). Pesquisa Agropecuária Brasileira, v.27, n.11, p.1551-1555, 1992.

BERCHIELLI, T.T.; ANDRADE, P.; FURLAN, C.L. et al. Avaliação de indicadores internos em ensaios de digestibilidade. Revista Brasileira de Zootecnia, v.29, n.3, p.830-833, 2000.

BOGGS, D.L.; MERKEL, R.A.; DOUMIT, M.E.et al. Livestock and carcasses. An integrated approach to evaluation, grading and selection. Dubuque, Iowa: Kendall/Hunt, 1998. 259p.

CARVALHO, S.; VERGUEIRO, A.; KIELING, R. et al. Avaliação da suplementação concentrada em pastagem de Tifton-85 sobre os componentes não carcaça de cordeiros. Ciência Rural. v.35, p.435-439, 2005.

CEZAR, M.F.; SOUSA, W.H. Carcaças caprinas e ovinas obtenção, avaliação e classificação. 1.ed. Uberaba: Agropecuária Tropical, 2007. v.1, 231p.

COLOMER-ROCHER, F.C. Factors influencing carcass quality. Carcass component and composition. In: INTERNATIONAL CONFERENCE ON GOATS, 4., 1987, Brasília. Proceedings... Brasília: EMBRAPA, 1987. p.181-194. 
COLOMER-ROCHER, F.C.; KIRTON, A.H.; MERCER, G.J.K et al. Carcass composition of New Zealand Saanen goats slaughtered at different weights. Small Ruminant Research, v.7, p.161-173, 1992.

EMPRESA BRASILEIRA DE PESQUISA AGROPECUÁRIA EMBRAPA. Manual de métodos de análise de solo. 2.ed. Rio de Janeiro: EMBRAPA CNPS, 1997. 212p.

FUEMAYOR, O.E.; CLAVERO, T. The effect of feeding system on carcass characteristics, non-carcass components and retail cut percentagens of lambs. Small Ruminant Research, v.34, p.57-64, 1999.

GONZAGA NETO, S.; SILVA SOBRINHO, A.G.; ZEOLA, N.M.B.L. et al. Características quantitativas da carcaça de cordeiros deslanados Morada Nova em função da relação volumoso: concentrado na dieta. Revista Brasileira de Zootecnia, v.35, n.4, p.1487-1495, 2006.

GRANDE, P.A.; ALCALDE, C.R.; MACEDO, F.A.F. et al. Desempenho e caracterísicas de carcaça de cabritos da raça Saanen recebendo rações com farelo de glúten de milho e/ou farelo de soja. Acta Scientiarum, v.25, n.2, p.315-321, 2003.

HASHIMOTO, J.H.; ALCADE, C.R.; SILVA, K.T. et al. Características de carcaça e da carne de caprinos Bôer x Saanen confinados recebendo rações com casca do grão de soja em substituição ao milho. Revista Brasileira de Zootecnia, v.36, n.1, p.165-173, 2007.

KOUAKOU, B.; GOETSCH, A.L.; PATIL, A.R. et al. Visceral organ mass in wethers consuming low-to moderate-quality grasses. Small Ruminant Reserach, v.26, p.69-80, 1997.

LUCAS, R.C. Efeito do genótipo sobre as características quantitativas e qualitativas da carcaça de caprinos terminados em pastagem nativa. 2007. 65f. Dissertação (Mestrado em Zootecnia) - Universidade Federal de Campina Grande, Patos, 2007.

MADRUGA, M.S.; NARAIN, N.; DUARTE, T.F. et al. Características químicas e sensoriais de cortes comerciais de caprinos SRD e mestiços de Bôer. Ciência Tecnologia Alimentar, v.25, n.4, p.713-719, 2005.

MATTOS, C.W.; CARVALHO, F.F.R.; DUTRA JR., W.M. et al. Características de carcaça e dos componentes não carcaça de cabritos Moxotó e Canidé submetidos a dois níveis de alimentação. Revista Brasileira de Zootecnia, v.35, n.5, p.2125-2134, 2006.

MONTE, A.L.S.; SELAIVE-VILLARROEL, A.B.; OLIVEIRA, A.N. et al. Rendimento de cortes comerciais e composição tecidual da carcaça de cabritos mestiços. Revista Brasileira de Zootecnia, v.36, n.6, p.2127-2133, 2007.

MORON-FUENMAYOR, O.E.; CLAVERO, T. The effect of feeding system on carcass characteristics, non-carcass components and retail cut percentages of lambs. Small Ruminant Research, v.34, p.57-64, 1999.

OSÓRIO, J.C.S.; OSÓRIO, M.T.M.; JARDIM, P.O. et al. Métodos para avaliação da produção da carne ovina: "in vivo", na carcaça e na carne. Pelotas: Editora Universitária, 1998. 107p.

PEREIRA FILHO, J.M.; RESENDE, K.T.; TEIXEIRA, I.A.M.A. et al. Efeito da restrição alimentar no desempenho produtivo e econômico de cabritos F1 Boer x Saanen. Revista Brasileira de Zootecnia, v.34, n.1, p.188-196, 2005.

PEREZ, P.; MAINO, M.; MORALES, M.S. et al. Effects of goats milk and milk substitutes and sex on productive parameters and carcass composition of Creole kid. Small Ruminat Research, v.42, p.87-93, 2001.

ROSA, G.T.; PIRES, C.C.; SILVA, J.H.S. et al. Proporções e coeficientes de crescimento dos não-componentes da carcaça de cordeiros e cordeiras em diferentes métodos de alimentação. Revista Brasileira de Zootecnia, v.31, n.6, p.2290-2298, 2002.

ROTA, E.L.; OSÓRIO, M.T.M.; OSÓRIO, J.C.S. et al. Efeitos do cruzamento de carneiros texel com ovelhas corriedale e ideal sobre a qualidade da carne. Revista Brasileira Agrociência, v.10, n.4, p.487-491, 2004.

SANTOS, C.L.; PÉREZ, J.R.O.; SIQUEIRA, E.R. et al. Crescimento alometrico dos tecidos ósseo, muscular e adiposo na carcaça de cordeiros Santa Inês e Bergamácia. Revista Brasileira de Zootecnia, v.30, n.2, p.493-498, 2001.

SIERRA, L.; SAÑUDO, C.; ALCADE M.J. Calidad de la Canal em Cordeiros ligeros tipo ternasco: canales españolas y de importación. Informativo Técnico Econômico Agrário, v.88, n.1, p.88-94, 1992.

SILVA, D.J.; QUEIROZ, A.C. Análise de alimentos: métodos químicos e biológicos. 3.ed. Viçosa, MG: Editora UFV, 2002. 235p.

STATISTICAL ANALYSES SYSTEM - SAS. The SAS system for windows. Version 8.0. Cary: 1999. (CD-ROM).

TAVARES, A.M.A.; VÉRAS, A.S.C.; BATISTA, A.M.V. et al. Níveis crescentes de feno em dietas á base de palma forrageira para caprinos em confinamento:comportamento ingestivo.Acta Science Animal Scientiarum, v.27, n.4, p.497-504, 2005.

WARMINGTON, B.G.; KIRTON, A.H. Genetic and non-genetic influences on growth and carcass traits of goats. Small Ruminant Research, v.3, p.147-165, 1990.

YÁÑEZ, E.A. Desenvolvimento relativo dos tecidos e características da carcaça de cabritos Saanen, com diferentes pesos e níveis nutricionais. 2002. 85f. Tese (Doutorado em Zootecnia) - Universidade Estadual Paulista, Jaboticabal, 2002.

YÁÑEZ, E.A.; RESENDE, E.T.; FERREIRA, A.C.D. et al. Utilização das medidas biométricas para predizer características da carcaça de cabritos Saanen. Revista Brasileira de Zootecnia, v.33, n.6, p.1564-1572, 2004 